\title{
Personality and Risk-Taking
}

\author{
Kipman $U^{1 *}$, Weiß $M^{2}$, Bartholdy $S^{3}$, Schiepek $G^{4}$ \\ and Aichhorn $\mathrm{W}^{4}$ \\ ${ }^{1}$ University of Salzburg, Austria \\ ${ }^{2}$ University of Graz, Austria \\ ${ }^{3}$ University of Greifswald, Germany \\ ${ }^{4}$ Paracelsus Medical Private University, Austria \\ *Correspondling author: Kipman U, College of \\ Education, University of Salzburg, Akademiestraße 23, \\ 5020 Salzburg, Austria
}

Received: October 21, 2021; Accepted: November 15, 2021; Published: November 22, 2021

\section{Abstract}

Risk-taking manifests itself in a variety of everyday actions, for some people more, for some less. The purpose of this study is to find the reason for these differences by examining the effects of various influencing factors such as gender, personality traits, self-confidence, self-reflection, self-control and affective parameters, like anxiety, on risk-taking behavior. For this purpose, the participants, 1.020 adults, were given self-report measures such as the Risk-Taking Questionnaire for Risk Readiness Factors, the ReliabilityRelated Personality Test, the Big Five Plus One Personality Inventory, the Work-Related Behavior and Experience Pattern and the Objective Personality Battery. Results show a positive correlation between physical risk-taking and openness, self-confidence, and self-reflection, as well as a negative correlation with social adjustment. Furthermore, social risk-taking correlated positively with self-confidence and self-reflection, and negatively with social adjustment. Extraversion correlated positively with financial risk-taking, whereas risky behavior in financial contexts showed a negative relationship with social adjustment and self-control. Gender differences were most evident in physical risk-taking. Openness to problem solving and inner balance were associated with a reduced willingness to take risks. There was no significant relationship between anxiety and risk-taking, as well as no differences between psychiatric patients and healthy individuals in their risky behavior.

Keywords: Risk taking; Personality; Big5; Distancing ability; Decisiveness; Impulsivity

\section{Introduction}

Risk-taking is something nearly everyone does in his or her life at some point. Some people more, some people less than others. There are different kinds of risk-taking: for example, risk-taking in social and work-related contexts, or physical (e.g., extreme sport) and health risk-taking, like smoking, drinking or even drug use. So, why and in which contexts are some people willing to take more risks than others?

There are some theories which try to explain this. One of these theories is the prospect theory by Kahneman and Tversky [1,2], which indicates that risk-taking is related to the context of the situation. That means that a person chooses the risky way over the safe way in a situation where the choices are framed positively (e.g., the number of people who would be saved by vaccination). If the choice is framed in a negative way (e.g., the number of people who would not be saved), people are less willing to choose the risky way. Others provide evidence that certain personality traits, like impulsivity or sensation seeking, are the reason for risk-taking tendencies [3]. There are many studies which show this phenomenon [3-7]. Aside from sensation seeking, other personality traits have been associated with participation in risky activities. For example, extraversion and psychoticism were found to be related to risky behavior such as "promiscuity" $[3,8]$. In a study by Nicholson et al. [4], high scores in openness and extraversion, and low scores in neuroticism, agreeableness and conscientiousness were related to six dimensions of risks (recreation, health, career, finance, safety and social). Czerwonka [9] came to the same conclusion: risk takers have high scores in extraversion and low scores in conscientiousness.
What most of the previously mentioned studies (if included) have in common is the gender aspect. Many studies indicated that men are willing to take more risks than women $[4,5,9]$, especially in physical risk-taking [1]. Other researchers mentioned traits such as self-believing or self-control as relevant to risky behavior; like the research by Krueger and Dickson [10], which showed that the positive perception of oneself and one's competence in decision making leads to the willingness of taking more risks, in contrast to someone who does not see an opportunity but a threat in risktaking and therefore refrains from it. Furthermore, Bandura $[11,12]$ suggests that individuals with high levels of self-efficacy are, in general, confident with their own intellectual abilities, especially with their critical judgement of themselves. This means that individuals who think positively of their future performances are able to analyze themselves critically. So, self-efficacy likely intensifies self-reflected thinking. Therefore, one can assume that self-reflected people may take more risks, because of their awareness of their abilities. Freeman and Muraven [13] examined the role of self-control in risk-taking and found that low self-regulation was a direct cause of risk-taking. This result is consistent with the results from Zuckerman and Kuhlman [3], which showed a correlation between six domains of risk-taking and poor self-control mechanisms.

Besides that, many studies found a relation between low distress tolerance, which describes the capacity to endure and withstand negative psychological states [14], and risky behavior, like hurried, risky and aggressive driving [15,16], as well as substance abuse $[16,17]$. But in contrast, are only personality traits responsible for the differences in risk-taking, or does affect, especially fear, also play 
a major role? Research shows a consistent picture in this aspect: Anxious or anxiety sensitive people appear to have less willingness of taking risks than others [18-20]. Especially, people diagnosed with anxiety disorders showed significantly greater risk aversion than patients with other diagnoses or nonclinical controls [21]. Furthermore, Giorgetta et al. [19] indicated that anxiety patients were less happy after gains but also less sad after losses and that they also evinced less desire to change their choices after losses than did nonanxious patients. Stress also leads to risky behavior, as the work of Buckert et al. [22] shows. They found that economic decision making under risk is affected by acute psychosocial stress. This agrees with the result from van den Bos et al. [23], showing that people tend to make riskier choices if they have to decide under high stress. But what happens when the person is exposed to permanent stress and shows, for example, signs of burnout syndrome? Burnout is associated with a variety of symptoms, including reduced ability to distance oneself and reduced levels of inner calm and balance [24]. There are few studies on the effects of burnout and its symptoms on risk-taking. One of the few is the one by Michailidis and Banks [25], in which they could not find a significant relationship between burnout and risky decision-making. However, research shows negative relationships between both exhaustion and depersonalization with emotional stability [26]. Mood instabilities are, in turn, positively associated with trait impulsivity and risk-taking [27]. Thus, one could assume that emotional imbalance could lead to increased risk-taking.

The influence of others could also be an influence for taking more risks. This was shown in research by Gardner and Steinberg [28] in which they examined the peer influence on adolescents and adults. Results indicate that, overall, people take more risk and make more risky decisions when they are with their peers than when they are on their own. It must be mentioned that this effect occurred more often during middle and late adolescence than during adulthood. In addition, Hogg et al. [29] imply in their polarization theory that the risk-taking tendencies of the group members affect the direction of group effects, which means that individuals with risk-taking tendencies make even riskier choices when grouped together [28].

The purpose of the present study is to examine the abovementioned findings on personality traits, anxiety, and self-control, as well as to gain some new insights regarding risk-taking and specific aspects of personality.

\section{Materials and Methods}

\section{Participants}

The present study is based on data from 1.020 adults ( $56.7 \%$ male), ranging from 17 to 90 years. Regarding their educational background, $37.5 \%$ reported an apprenticeship certificate, $22.4 \%$ a high school degree and $27.5 \%$ a university degree; the remaining $12.6 \%$ did not finish school or only completed secondary modern school. $19.7 \%$ of participants were receiving a psychiatric treatment.

\section{Procedure}

For all statistical analyses, SPSS version 26.0 (2020) was used.

Linear regression analyses were performed to evaluate the impacts of gender, social background, and personality traits on risk-taking (physical risk-taking, social risk-taking, and financial risk-taking). The predictive strength of each variable was first assessed in a univariate model (e.g., impact of gender alone) and then in a multivariate model while controlling for the other variables respectively (e.g., impact of extraversion while controlling for gender, social background, and other personality traits). Missing data were imputed for up to $10 \%$ of participants.

Furthermore, several mediator models with risk-taking as outcome variable and possibly relevant variables as mediators will be examined.

\section{Instruments}

Risk-taking questionnaire for risk readiness factors: To measure the willingness to take risks (physical, social, and financial risks), the Risk-Taking Questionnaire for Risk Readiness Factors (FRF) [30] was used. This questionnaire is a standardized 49-item instrument measuring (1) the willingness to confront difficult, unfamiliar, physically hazardous situations and objects and to set aside concerns about one's health or physical safety (physical risk-taking), (2) the willingness to ignore norms in social situations, to consciously accept unpopularity and to behave independently of the approval or disapproval of others (social risk-taking), and (3) the willingness to enter into transactions in which the outcome is uncertain and the risks cannot be calculated, as well as to handle money carelessly and riskily (financial risk-taking).

Reliability-related personality test: To measure personality traits, the Reliability-Related Personality Test-Version 3 (VPT3) (Kuratorium für Verkehrssicherheit) was used. This multidimensional 70-item questionnaire obtains the respondent's selfassessments in relation to social behavior, emotional state/stability and his/her level of self-control and self-reflection. The following main variables are scored:

- $\quad$ Social expressiveness - self-confidence: Measure of the key basic dimension of social behavior known as "extraversion".

- Social adjustment: The level of social agreeableness or readiness to engage in conflict. This is a second important basic dimension of social behavior.

- Emotional responsiveness: The level of emotional instability, tension, irritation and anxiety.

- Self-control: The level of an individual's self-discipline, consistency, reliability, and adherence to norms.

- Self-reflection: The level of intellectual flexibility and nuanced thinking as a measure of self-reflection.

Big five plus one personality inventory: The Big Five Plus One Personality Inventory (B5PO) [32] assesses the Big Five dimensions of personality: Extraversion, Agreeableness, Conscientiousness, Neuroticism, Openness, and the additional dimension of Empathy. These relatively stable personality characteristics (known as traits) roughly determine the individual's everyday behavior. They can be used to predict future behavioral tendencies.

The following main variables were analyzed:

- Extraversion: Measure of behavioral tendencies in interpersonal situations (e.g., the level of dominance or sociability).

- Agreeableness: Measure of social competence (e.g., the 
level of respect or aggression).

- Conscientiousness: Measure of behavioral tendencies in the context of work or achievement (e.g., the level of discipline or reliability).

- Neuroticism/Emotional control: Measure of the ability to control one's own feelings (e.g., the level of impulsiveness or rationality).

- Openness: Measure of the willingness to be open to new experiences and values (e.g., the level of tolerance or loyalty).

- Empathy: Measure of the ability to understand and feel the emotions of others (e.g., the level of friendliness or helpfulness).

Work-related behavior and experience pattern: The following main variables are assessed by the Work-related Behavior and Experience Pattern (AVEM) [33]:

- Subjective importance of work in personal life

- Work-related ambition

- Willingness to work until exhausted

- $\quad$ Striving for perfection

- Distancing ability (ability to recuperate mentally from work)

- Tendency to resignation in the face of failure

- $\quad$ Proactive problem-solving (active and optimistic attitude)

- Inner calm and balance (experience of emotional stability)

- $\quad$ Experience of success at work (satisfaction)

- $\quad$ Satisfaction with life

- $\quad$ Experience of social support

For the present study, we extracted results from three scales Inner Calm and Balance (experience of emotional stability), Proactive Problem-Solving (active and optimistic attitude), and Distancing Ability -, as there are hints that there may be a relation to risk-taking in the literature.

Objective personality battery: The Objective Personality Battery (AHA) [34] assesses the respondent's cognitive style (i.e., impulsiveness versus reflectivity) and the motivational dimensions of aspiration level, frustration tolerance, and achievement motivation. The Objective Personality Battery therefore provides information on behavior and motivation in stressful situations.

The following variables were extracted, as they may be related to risk-taking:

- Impulsiveness vs. Reflexivity: Measure of the prominence of a style.

- Frustration Tolerance: Measure of the extent to which the respondent is influenced by negative feedback.

- Decisiveness: Measure of the determination when making decisions.

\section{Results}

In the following, we describe the influences of all predictors on all risk-taking scores for the whole sample. Adults receiving a psychiatric treatment did not differ from healthy adults in their risktaking scores $(\mathrm{z}<10.98)$. Due to the sample size, small coefficients are also statistically significant. Thus, we only report practically relevant influences $(\beta \geq 0.20)$, although other variables may also have a significant impact on risk-taking (e.g., gender on physical risk-taking, $\mathrm{p}=0.036)$.

Variables which remain practically relevant in the combined models are marked with a \#. We also provide mediator models measuring the direct and indirect influence of the interesting significant and practically relevant variables on risk-taking (Table 1).

A first important finding is that all types of risk-taking increased with higher levels of extraversion and neuroticism, openness to experience, self-assurance, and the ability to make decisions. Openness to problem solving and inner balance had a negative impact on risktaking. Tolerance of frustration increased social risk-taking but decreased physical and financial risk-taking. The reported variables were significant and practically relevant univariate predictors of risktaking in all domains.

For at least one, but not all domains, we also found significant and practically relevant predictors. Impulsivity and the ability to distance oneself from the expectations of others were further significant and practically relevant predictors for physical risk-taking: the higher impulsivity and the lower the ability to distance oneself from the expectations of others, the higher the score of physical risk-taking.

Regarding social risk-taking, the subject's social background, Table 1: Results of separate regression analyses to predict physical, social, and financial risk-taking. Displayed values represent beta coefficients.

\begin{tabular}{|c|c|c|c|}
\hline & $\begin{array}{l}\text { Physical } \\
\text { Risk-Taking }\end{array}$ & $\begin{array}{l}\text { Social } \\
\text { Risk- } \\
\text { Taking }\end{array}$ & $\begin{array}{l}\text { Financial } \\
\text { Risk-Taking }\end{array}$ \\
\hline Gender & 0.126 & -0.008 & -0.07 \\
\hline Social Background & 0.115 & $0.260^{\star}$ & 0.051 \\
\hline Extraversion & $0.314^{*}$ & $0.602^{\star}$ & $0.435^{\star}$ \\
\hline Agreeableness & -0.197 & -0.174 & $-0.298^{*}$ \\
\hline Conscientiousness & -0.042 & 0.106 & 0.11 \\
\hline Neuroticism & $0.321^{*}$ & $0.208^{\star}$ & $0.314^{*}$ \\
\hline Openness to Experience & $0.333^{*}$ & $0.510^{\star}$ & $0.563^{*}$ \\
\hline Empathy & 0.058 & $0.263^{\star}$ & 0.053 \\
\hline Self-Assurance & $0.234^{\star *}$ & $0.346^{\star \#}$ & $0.270^{\star *}$ \\
\hline Social Adjustment & -0.135 & $-0.260^{*}$ & -0.14 \\
\hline Anxiety & -0.057 & 0.004 & 0.175 \\
\hline Self-Control & -0.108 & 0.091 & $-0.300^{* \#}$ \\
\hline Reflectivity & 0.188 & $0.266^{\star}$ & 0.018 \\
\hline Decision-Making (Decisiveness) & $-0.243^{*}$ & $-0.354^{*}$ & $-0.214^{*}$ \\
\hline Impulsivity & $0.415^{\star}$ & 0.085 & 0.154 \\
\hline Tolerance of Frustration & $-0.415^{\star}$ & $0.251^{*}$ & $-0.278^{*}$ \\
\hline $\begin{array}{l}\text { Ability to Distance Oneself From } \\
\text { the Expectations of Others }\end{array}$ & $-0.313^{*}$ & $0.333^{\star \#}$ & -0.01 \\
\hline Openness to Problem Solving & $-0.619^{* \#}$ & $-0.264^{*}$ & $-0.248^{*}$ \\
\hline Inner Balance & $-0.377^{* \#}$ & $-0.226^{*}$ & $-0.461^{*}$ \\
\hline
\end{tabular}

Note: "Practically relevant in the combined model; "Practically relevant (effect size $>0.20$ ). 
empathy, reflectivity, and the ability to distance oneself from the expectations of others increased the willingness to take social risks, whereas high social adjustment had a negative impact on social risktaking. Agreeableness was, in addition to the variables mentioned above, a negative predictor for financial risk-taking.

Controlling for all other practically relevant and significant predictors in a multivariate analysis, the effect of self-assurance was still practically relevant for all three domains. Openness to problemsolving and inner balance remained significant and practically relevant even when controlling for all other relevant variables in the univariate models. Concerning physical risk-taking, the ability to distance oneself from the expectations of others was - additionally to self-assurance - still significant and practically relevant when analyzing its impact on social risk-taking. Furthermore, self-control was a significant and practically relevant negative predictor for financial risk-taking in the combined model.

A mediation model showed a mediating effect of self-assurance on physical risk-taking when regressing the ability to distance oneself from the expectations of others on the willingness to take physical risks $(\mathrm{z}=2.08)$.

\section{Discussion}

The present study examined relationships between multiple personality traits and physical, social, as well as financial risk-taking. Results mostly confirmed findings from previous research on the topic.

A moderate positive relationship was found between impulsivity and the level of only physical, but not social or financial risk-taking, which thereby partially replicated previous findings [3-7]. This clear distinction can be explained by the fact that potentially risky social and financial decisions are often considered more thoroughly than physical decisions, hence reducing the influence of impulsivity.

Extraversion and neuroticism, on the other hand, were consistently positively associated with higher levels of risk-taking in all three domains $[3,4,8,9]$. The closest relationship was found between extraversion and social risk-taking. This emphasizes the potentially pathological nature of high levels of extraversion, i.e., extraversion appears to increase a person's tendency to make more risky decisions. This interpretation is consistent with Gardner and Steinberg's [28] study, which suggests substantial peer influences on decision-making not only in adolescents, but also in adults. The positive relationships between both extraversion and the ability to distance oneself from the expectations of others with social risk-taking furthermore support the related polarization theory proposed by Hogg et al. [29], which stated that individuals with already high risk-taking tendencies would polarize each other if they were interacting in groups, thereby further increasing each person's tendency to take risks [28]. Also, Nicholson et al. (2005) and Czerwonka (2019), for instance, found that low scores in conscientiousness were associated with high scores in risktaking, but this relationship was not found in the present data. The results replicate Nicholson et al.'s [4] findings regarding a positive relation between openness and risk-taking, as well as a negative relation between agreeableness and (financial) risk-taking. A strong negative relationship was also found between openness to problemsolving and physical risk-taking.
Another interesting result was a statistically significant gender difference in the willingness to take risks (with higher scores found in men), which was consistent with previous studies [1,4,5,9], but surprisingly was not practically meaningful.

Based on a few previous studies, possible influences of self-belief (self-assurance) and self-control were examined and it was found that self-assurance - i.e., a positive self-perception and belief in one's own competence - appeared to have a small to moderate influence on each domain of risk-taking [10]. Self-control, on the other hand, only had a negative influence on financial risk-taking, indicating that better self-regulation and control may be a reliable trait to keep a person safe from financial risks.

Another interesting result concerns the positive association between a person's level of self-reflectivity and their tendency to take social risks. This is consistent with Bandura's hypothesis [11,12] of high levels of self-efficacy and self-reflectivity as the motivating forces for someone to take more risks, which would therefore be caused by the person's positive awareness of their abilities. Hence, the present results contradict the studies by Freeman and Muraven [13] and Zuckerman and Kuhlman [3], which found opposite relationships. Related to this, decisiveness (i.e., determination in decision-making) was negatively correlated with all three domains of risk-taking.

Inner balance was negatively associated with all three domains of risk-taking, whereas distress tolerance (i.e., frustration tolerance) was only found to be negatively correlated with physical and financial risk-taking [14-17,27]. Surprisingly and contrary to much empirical work [18-21], no significant relationship was found between anxiety and risk-taking, and no significant differences in risk-taking were found between psychiatric patients and healthy controls.

Finally, a differential influence of the ability to distance oneself from the expectations of others was found: a higher ability of selfdistancing was associated with less physical risk-taking, but positively correlated with social risk-taking. This gives insights for the field of Burnout- and stress-related symptoms and their treatment [24,25].

\section{References}

1. Byrnes JP, Miller DC \& Schafer WD. Gender differences in risk taking: a meta-analysis. Psychological Bulletin. 1999; 125: 367.

2. Kahneman D \& Tversky A. Prospect theory: An analysis of decision under risk. Econometrica: Journal of the Econometric Society, an Internet. Society for the Advancement of Economic Theory in Its Relation to Statistics and Mathematics. 1979; 47: 263-291.

3. Zuckerman M, Kuhlman DM. Personality and risk-taking: Common biosocial factors. Journal of Personality. 2000; 68: 999-1029.

4. Nicholson N, Soane E, Fenton-O'Creevy M \& Willman P. Personality and domain-specific risk taking. Journal of Risk Research. 2005; 8: 157-176.

5. Zaleskiewicz T. Beyond risk seeking and risk aversion: personality and the dual nature of economic risk taking. European Journal of Personality. 2001; 15: S105-S122.

6. Zuckerman M. Sensation seeking: Beyond the optimal level of arousal. Erlbaum. 1979.

7. Zuckerman M. Behavioral expressions and biosocial bases of sensation seeking. Cambridge University Press. 1994.

8. Eysenck HJ. Sex and personality. University of Texas Press. 1976.

9. Czerwonka M. Cultural, cognitive and personality traits in risk-taking behaviour: Evidence from Poland and the United States of America. Taylor 
and Francis Group and Juraj Dobrila University of Pula, Faculty of economics and tourism Dr. Mijo Mirković. 2019.

10. Krueger N \& Dickson PR. How believing in ourselves increases risk taking Perceived self-efficacy and opportunity recognition. Decision Sciences. 1994; 25: $385-400$

11. Bandura A, Caprara GV, Barbaranelli C, Pastorelli C \& Regalia C Sociocognitive self-regulatory mechanisms governing transgressive behavior. Journal of Personality and Social Psychology. 2001; 80: 125-135.

12. van Seggelen-Damen I \& van Dam K. Self-reflection as a mediator between self-efficacy and well-being. Journal of Managerial Psychology. 2016; 31: 1833.

13. Freeman N \& Muraven M. Self-Control Depletion Leads to Increased Risk Taking. Social Psychological and Personality Science. 2010; 1: 175-181.

14. Simons JS \& Gaher RM. The Distress Tolerance Scale: Development and Validation of a Self-Report Measure. Motivation and Emotion. 2005; 29: 83102.

15. Beck KH, Daughters SB \& Ali B. Hurried driving: Relationship to distress tolerance, driver anger, aggressive and risky driving in college students. Accident; Analysis and Prevention. 2013; 51: 51-55.

16. Beck KH, Ali B \& Daughters SB. Distress tolerance as a predictor of risky and aggressive driving. Traffic Injury Prevention. 2014; 15: 349-354.

17. Buckner JD, Keough ME \& Schmidt NB. Problematic alcohol and cannabis use among young adults: The roles of depression and discomfort and distress tolerance. Addictive Behaviors. 2007; 32: 1957-1963.

18. Broman-Fulks JJ, Urbaniak A, Bondy CL \& Toomey KJ. Anxiety sensitivity and risk-taking behavior. Anxiety, Stress, and Coping. 2014; 27: 619-632.

19. Giorgetta C, Grecucci A, Zuanon S, Perini L, Balestrieri M, Bonini N, et al. Reduced risk-taking behavior as a trait feature of anxiety. Emotion (Washington, D.C.). 2012; 12: 1373-1383.

20. Maner JK \& Schmidt NB. The role of risk avoidance in anxiety. Behavior Therapy. 2006; 37: 181-189.

21. Maner JK, Richey JA, Cromer K, Mallott M, Lejuez CW, Joiner TE, et al. Dispositional anxiety and risk-avoidant decision-making. Personality and Individual Differences. 2007; 42: 665-675.

22. Buckert M, Schwieren C, Kudielka BM \& Fiebach CJ. Acute stress affects risk taking but not ambiguity aversion. Frontiers in Neuroscience. 2014; 8: 82

23. van den Bos $R$, Harteveld $M$ \& Stoop $H$. Stress and decision-making in humans: Performance is related to cortisol reactivity, albeit differently in men and women. Psychoneuroendocrinology. 2009; 34: 1449-1458.

24. Schaarschmidt $U$ \& Kieschke U. Burnout als Muster arbeitsbezogenen Verhaltens und Erlebens. Persönlichkeitsstörungen: Theorie Und Therapie. 2012; 16: 116-124.

25. Michailidis E \& Banks AP. The relationship between burnout and risk-taking in workplace decision-making and decision-making style. Work \& Stress. 2016; 30: 278-292.

26. Ghorpade J, Lackritz J \& Singh G. Burnout and Personality. Journal of Career Assessment. 2007; 15: 240-256.

27. Peters EM, Bowen R \& Balbuena L. Mood Instability and Trait Anxiety as Distinct Components of Eysenckian Neuroticism with Differential Relations to Impulsivity and Risk Taking. Journal of Personality Assessment. 2020; 102: 337-347.

28. Gardner M \& Steinberg L. Peer influence on risk taking, risk preference, and risky decision making in adolescence and adulthood: An experimental study. Developmental Psychology. 2005; 41: 625-635.

29. Hogg MA, Turner JC \& Davidson B. Polarized Norms and Social Frames of Reference: A Test of the Self-Categorization Theory of Group Polarization. Basic and Applied Social Psychology. 1990; 11: 77-100.

30. Schmidt L. Fragebogen zur Erfassung verschiedene Risikobereitschaftsfaktoren (FRF). Kleine Fachbuchreihe Des Kuratoriums Für Verkehrssicherheit (KFV). 1985: 23.

31. Kuratorium für Verkehrssicherheit. Verlässlichkeitsbezogener Persönlichkeitstest - Version 3. Schuhfried $\mathrm{GmbH}$.

32. Holocher-Ertl S, Kubinger KD \& Menghin S. Big Five Plus One Persönlichkeitsinventar (B5PO) [Big Five Plus One Personality Inventory (B5PO)] [Software and Manual]. Mödling: Dr. G. Schuhfried GmbH. 2003.

33. Schaarschmidt $U$ \& Fischer AW. AVEM-ein diagnostisches Instrument zur Differenzierung von Typen gesundheitsrelevanten Verhaltens und Erlebens gegenüber der Arbeit. 1997.

34. Kubinger KD \& Ebenhöh $H$. Arbeitshaltungen (AHA): Objektiver Persönlichkeitstest. Mödling, Austria: Schuhfried. 1996. 